\title{
Effect of Greenhouse Gas Emissions on the Predictability of Rainfall, Temperature and Solar Radiation in Port Harcourt, Nigeria
}

\author{
Tikyaa EV*, Echi IM, Isikwue BC and Amah AN
}

Department of Physics, University of Agriculture Makurdi, Benue State, Nigeria

Review Article

Volume 4 Issue 1

Received Date: May 06, 2020

*Corresponding author: Emmanuel V Tikyaa, Department of Physics, University of Agriculture Makurdi, Benue State, Nigeria, Tel: 07032096960; Email: evtikyaa@gmail.com
Published Date: June 22, 2020

\section{Abstract}

This research applies the tools of statistical analysis and nonlinear dynamics on rainfall, average temperature and solar radiation records over Port Harcourt, Nigeria, so as to quantify the signatures of chaos and analyze the trend of predictability of the weather over the last three decades. Quantifying the degree of chaos and the predictability of a dynamical system like weather time series is carried out by computing the largest Lyapunov exponents and then taking the inverse to get the predictability of the system. Rosenstein's algorithm was deployed in evaluating the yearly values of the largest Lyapunov exponents and predictability for each data set and the results obtained were subjected to Correlation analysis, Mann-Kendall test and Sen's slope estimator so as to estimate the trends and relationship between the predictability of these parameters and the total $\mathrm{CO}_{2}$ emissions recorded in the region over the three decade period. The results obtained show that the trends in the Lyapunov exponents and predictability of rainfall, average temperature and solar radiation in Port Harcourt are all significant; with the relationship between the predictabilities of the meteorological variables and the annual Total $\mathrm{CO}_{2}$ emissions found to have a decreasing trend. This implies the prevalence of fluctuating and extreme weather as well as failure in the accurate short-term prediction of the weather over Port Harcourt in the near future as a result of greenhouse gas emissions from oil exploration and refining activities.

Keywords: Chaos; Greenhouse gases; Lyapunov exponents; Predictability; Man-Kendall test'; Sen’s slope estimator

\section{Introduction}

Chaos is an aperiodic long-term behavior in a deterministic system that exhibits sensitive dependence on initial conditions. Edward Lorenz discovered the phenomena of chaos in the atmosphere while devising a crude computer model that produced an impressive simulation of weather patterns [1]. This discovery of chaotic dynamics of the atmosphere spelled doom for long-term weather forecasting i.e. the best one can hope to achieve is to predict the weather a few days in advance [2] and that the atmosphere might have an intrinsic limit of predictability [3]. After further research, scientists estimate that even with near-perfect computer models and measurements, they could only forecast the day-to-day weather two to three weeks into the future while average weekly weather is less chaotic and monthly average conditions are even more predictable. Thus meteorologists may never be able to forecast a particularly hot or cold day several months in advance, but can forecast a hot or cold week, month or year because chaotic effects become less pronounced over longer-term averages.

Chaos is characterized by extreme sensitivity to changes in initial conditions [4] and this can be quantified by the Lyapunov exponents (LE) and Lyapunov vectors (LV). Lyapunov exponent is a measure of the rate of exponential 
divergence of initially close state-space trajectories (data trend) and this estimates the amount of chaos in the system [5]. The leading LE can be defined as the limit of the maximal time-averaged logarithmic growth rate of the distance between two nearby model states, as the integration interval increases without bound. The leading LV gives the direction in phase space (which depends on the specific initial state, in contrast to the LE which is a fundamental constant of the system) for which this maximum growth rate is attained. Chaos is indicated by a leading LE greater than zero, indicating that initially similar model states diverge over time [6]. Predictability or error folding time is the time within which it is possible to predict a system forward accurately [7]. It is the multiplicative inverse of the largest Lyapunov exponent [8].

Greenhouse effect is the rise in temperature that the earth experiences because certain gases in the atmosphere (such as ozone, water vapor, carbon dioxide, nitrous oxide, methane and chlorofluorocarbons) trap energy from the sun [9]. Without these gases, heat would escape back into space and earth's average temperature would be about $60^{\circ} \mathrm{F}$ colder. Because of how they warm our world, these gases are referred to as greenhouse gases [10]. Global warming is simply that net increase in atmospheric temperatures over the globe and this is mostly associated with the release of harmful greenhouse gases from human activity, particularly the burning of fossil fuels which release carbon dioxide and other gases into the atmosphere, which deplete the ozone layer and trap excess heat. The Intergovernmental Panel on Climate Change (IPCC) stated that the global surface temperature has increased by $0.74 \pm 0.18{ }^{\circ} \mathrm{C}(1.33 \pm 0.32$ ${ }^{\circ} \mathrm{F}$ ) during the last 100 years ending in 2005 and this is attributed to the increase in anthropogenic greenhouse gas concentrations [11]. The consequence of this is drought, flooding, varnishing glaciers, rising sea levels, disintegrating polar ice and melting permafrost, deforestation and desertification, outbreak of disease, damage to coral reefs, increased hurricanes and tornadoes, shifting cycles/ extinction of plant and animal species etc. [12].

Some of the chaotic components in the climatic system include: El Nino, fluid turbulence and most importantly greenhouse effect-which has a much more long-term influence [13]. Now what effects do greenhouse gases and global warming have on the chaoticity and predictability of the weather in Nigeria over the last three decades? That is the subject of investigation in this research work.

The objectives of this work are as follows:

1. To compute the annual Lyapunov exponents and predictability of rainfall, temperature and solar radiation in Port Harcourt, Nigeria from 1977-2012;

2. To plot the predictability of rainfall, temperature and solar radiation in Port Harcourt Nigeria from 1977-
2012 so as to view the trend.

3. To correlate and investigate the effect of greenhouse gas emissions on the trend of chaos in the climate of Port Harcourt based on available data on annual total greenhouse gas and $\mathrm{CO}_{2}$ emissions in Nigeria from 1977-2012.

In essence, the outcome of this work will tell us whether the accuracy of weather forecasts over Port Harcourt will experience more failures or not as a result of the annual increase in the emission of greenhouse gases (particularly $\mathrm{CO}_{2}$ ) into the atmosphere from oil exploration and refining activities.

\section{Theoretical Considerations}

\section{Phase Space Reconstruction}

Before computing the Lyapunov exponents, phase space reconstruction has to be done so as to draw out a multidimensional description of system in an embedded space called state space. The main reason for a possible phase space reconstitution is that nonlinear systems are usually characterized by self-interaction, so that a single variable may carry information about the whole system [14]. This can be achieved using the method of delay (MOD) [15], [16].

Consider a time series $\left\{\mathrm{x}_{1}, \mathrm{x}_{2}, \ldots, \mathrm{x}_{\mathrm{N}}\right\}$, where $\mathrm{N}$ is the number of observations, the attractor can be reconstructed in a m-dimensional phase space of delay coordinates by forming the vectors:

$$
X_{n}=\left[x_{n}, x_{n+\tau}, x_{n+2 \tau}, \ldots, x_{n+(m-1) \tau}\right]
$$

where $\tau$ is the delay time, and the integer $m$ is the embedding dimension. In practical terms, the delay time (or time lag) $\tau$ must be the shortest time over which there are clearly measurable variations in the observable [16].

The delay time is evaluated in this work using the method of Average Mutual Information (AMI) developed by Cellucci et al. [17]. The value of the lag length at the first local minimum of the AMI plot corresponds to the optimum selection of the delay time. The minimum embedding dimension, $\mathrm{m}$ is on the other hand is computed using the method of "False Nearest Neighbors (FNN)" which was developed by Kennel et al. [18]. This technique operates by checking the neighborhood of points embedded in projection manifolds of increasing dimension and eliminating 'false neighbors.' This means that points that seem to lie close together due to this arrangement are separated by choosing higher embedding dimensions. A plot of the percentage of FNN plotted against increasing embedding dimension usually exhibits a monotonic 
decreasing curve and the minimum embedding dimension can be evaluated from the point where the percentage of FNN drops to almost zero or a minimum value [19].

\section{Computation of Lyapunov Exponents and Predictability}

Rosenstein et al. (1992) proposed an approach for finding the largest Lyapunov exponents of small data sets. The approach is used in this work because it is easier to operate, more reliable even for small data sets ( $<500$ points) and more economical to use as smaller amount of calculation is required to obtain the desired results. The algorithm for Rosenstein's method is as follows [14]:

1. Input the data i.e. the time series as a single column vector $\left\{x_{1}, x_{2}, x_{3} \ldots x_{n}\right\}$.

2. Compute the delay time (time lag) $\tau$ using the method of average mutual information (AMI) and the mean period, using the fast Fourier transform. The mean period or periodicity $\mathrm{P}$ in a time series was used to remove cyclic/ seasonal variations in the time series data (seasonal differencing). If the data is not made stationary, the phase space reconstruction will not be properly achieved and the deterministic components of the data will not be adequately revealed leading to misleading results in the computed values of Lyapunov exponents and predictability [20, 21].

3. Estimate the embedding dimension $m$, using either the correlation dimension method or the method of false nearest neighbor (FNN).

4. Reconstitute the phase-space using the values of $\tau$ and $\mathrm{m}$ based on the method of delays (MOD).

5. Determine the nearest neighbor of each phase-point and set a boundary for short term seperation. The nearest neighbor, , is found by searching for the point that minimizes the distance to the particular reference point,.

$$
d_{j}(0)=\min _{x \hat{j}}\left\|x_{j}-x_{\hat{j}}\right\| \text {, for all }|j-\hat{j}|>Q
$$

Where is the initial separation between the $j$ th point and its nearest neighbor. The parameter $Q$ is the mean orbital period and is obtained from the mean frequency of the power spectrum [14].

6. Estimate the Euclidean distance between $i$ discrete time steps for each pair of neighbors

$$
d_{j}(i)=\left|x_{j+1}-x_{\hat{j}+1}\right|, i=1,2, \ldots, \min (M-j, M-\hat{j})
$$

7. Based on the assumption that the jth pair of nearest neighbors diverges approximately at a rate given by the

$$
\text { largest Lyapunov exponent: } \quad d_{j}(i) \approx C_{j}(i) e^{\lambda(i d t)}
$$

Where $C_{j}$ is the initial separation (i.e. $\left.d_{j}(0)\right)$ and $\mathrm{dt}$ is the sampling interval, the natural logarithm of both sides when taken, gives the equation:

$$
\operatorname{Ind}_{j}(i) \approx \operatorname{InC}_{j}(i)+\lambda(i d t)
$$

By making a typical plot of the average exponential divergence against the discrete time step (), the slope of the dashed line fitted to the curves is equal to the theoretical value of the largest Lyapunov exponent, $\lambda$. This can easily be achieved by fitting the curve to a regression line using the method of least squares [19]. The Lyapunov (error folding) time or predictability $\mathrm{T}$ is the inverse of the largest Lyapunov exponent $\lambda$ and is expressed as [7]:

$$
\mathrm{T}=\frac{1}{\lambda}(6)
$$

\section{Trend Analysis}

Due to the random and fluctuating nature of the results obtained, trend analysis was carried out using the following statistical tools:

1. Firstly, correlation coefficients of the annual Lyapunov exponents and time as well as the annual Lyapunov exponents and Total $\mathrm{CO}_{2}$ emissions excluding LULUCF will be computed to determine the strength of the linear relationship between these variables.

2. Secondly, the presence of a monotonic increasing or decreasing trend was tested using the non-parametric Mann-Kendall test.

3. Thirdly, the slope of a linear trend is estimated with the nonparametric Sen's slope estimator.

\section{Correlation Coefficient}

The Linear correlation coefficient (Pearson product moment correlation coefficient) $r$, measures the strength and the direction of a linear relationship between two variables. It is mathematical given by [22]:

$$
r=\frac{n \sum x y-\left(\sum x\right)\left(\sum y\right)}{\sqrt{n\left(\sum x^{2}\right)-\left(\sum x\right)^{2} \sqrt{n\left(\sum y\right)^{2}-\left(\sum y\right)^{2}}}}
$$

1. The value of $r$ is such that it always takes a value between -1 and +1 , with +1 or -1 indicating a perfect correlation (i.e. all points would lie along a straight line, having a residual of zero).

2. A correlation coefficient close to or equal to zero indicates no relationship between the variables.

3. A correlation greater than 0.8 is generally described as strong, whereas a correlation less than 0.5 is generally described as weak. 
4. A positive correlation coefficient indicates a positive (upward) relationship, positive values indicates a relationship between $\mathrm{x}$ and $\mathrm{y}$ variables such that as values for $\mathrm{x}$ increases, values for $\mathrm{y}$ also increase.

5. A negative correlation coefficient indicates a negative (downward) relationship between the variables. Negative values of $r$ indicate a relationship between $\mathrm{x}$ and $\mathrm{y}$ such that as values for $\mathrm{x}$ increase, values for $y$ decrease.

\section{Mann-Kendall Analysis}

The non-parametric Mann-Kendall test is usually used to detect trends that are monotonic but not necessarily linear. The null hypothesis in the MannKendall test is that the data are independent and randomly ordered. It does not require the assumption of normality, and only indicates the direction but not the magnitude of significant trends. The Mann-Kendall test statistic $S$ is computed using the formula [23]:

$$
S=\sum_{k=1}^{n-1} \sum_{j=k+1}^{n} \operatorname{sign}\left(x_{j}-x_{k}\right)
$$

Where $x_{j}$ and $x_{k}$ are the annual values of Lyapunov exponents in years $j$ and $k, j>k$, respectively. The sign ( ) function is defined as [24]:

$$
\operatorname{sign}\left(x_{j}-x_{k}\right)=\left\{\begin{array}{ll}
1 & \text { if } x_{j}-x_{k}>0 \\
0 & \text { if } x_{j}-x_{k}>0 \\
-1 & \text { if } x_{j}-x_{k}>0
\end{array}\right\}
$$

A very high positive value of $S$ is an indicator of an increasing trend, while a very low negative value indicates a decreasing trend [25].

Furthermore, it is required that the probability associated with $\mathrm{S}$ and the sample size, $\mathrm{n}$ be computed, so as to statistically quantify how significant the trend is. The variance of the statistic $S$ may be computed as [26]:

$$
E(s)=0, \operatorname{var}(s) \approx \frac{n(n-1)(2 n+5)}{18}
$$

The Man-Kendall parameter $S$ and variance $\operatorname{VAR}(S)$ are used to compute the test statistic $Z$ as follows [24]:

$$
Z=\left\{\begin{array}{ll}
\frac{s-1}{\sqrt{\operatorname{VAR}(\mathrm{S})}} & \text { if } S>0 \\
0 & \text { if } S>0 \\
\frac{s+1}{\sqrt{\operatorname{VAR}(\mathrm{S})}} & \text { if } S<0
\end{array}\right\}
$$

The Z statistic follows a normal distribution and is tested at $95 \%$ level of significance $\left(Z_{0.025}=1.96\right)$. Its value describes the trend as follows [26]:

1. The trend is said to be decreasing if $Z$ is negative and the absolute value is greater than the level of significance,

2. The trend is said to be increasing if $\mathrm{Z}$ is positive and greater than the level of significance.

3. There is no trend if the absolute value of $\mathrm{Z}$ is less than the level of significance.

\section{Sen's Slope Estimator}

This is a simple linear regression model used to detect trends in data using parametric models. The Sen's nonparametric test estimates the true slope of an existing trend (as change per year). The Sen's method is used in cases where the trend can is assumed to be linear:

$$
y(t)=Q t+B(12)
$$

Where $\mathrm{Q}$ is the slope, $\mathrm{B}$ is a constant and $t$ is time.

$$
\text { Sen' s estimator, } Q=\underbrace{\text { median }}_{j>k}\left(\frac{x_{j}-x_{k}}{j-k}\right)
$$

For $n$ values $x_{j}$ in the time series there will be as many as $N=\frac{n(n-1)}{2}$ slope estimates $Q_{i}$ of which the median value gives the Sen's estimator, Q. In order to get an estimate of the intercept B in equation (13), the $n$ values of differences $x_{i}-Q t_{i}$ are calculated. The median of these values gives an

estimate of $B$ [27]. These statistical tests were executed using MATLAB software application [28].

\section{The Study Area and Data used}

\section{The study area}

Port Harcourt, the capital of Rivers state lies along the Bonny River and is located in the Niger Delta region in the South-South geopolitical zone of Nigeria with coordinates $4^{o} 75^{\prime} N, 7^{\circ} 00^{\prime} E$. With a population of about $1,382,592$, the

town was named after Lewis Vernon Harcourt in 1913 by the then Governor of Nigeria Sir Fredrick Lord Lugard. After the discovery of oil in 1956 at Oloibiri, the economy of the town was transformed with the first oil export through the city in 1913 [29]. Today, several oil companies currently have offices in the city including Royal Dutch Shell, Chevron and ExxonMobil. The Port Harcourt Refining Company Limited which was founded since 1965 and owned by the Nigerian National Petroleum Corporation (NNPC) is also located in the city [30]. All these industries contribute a very large percentage to the total $\mathrm{CO}_{2}$ and greenhouse gas emissions across the State and in the South-South region of Nigeria. 


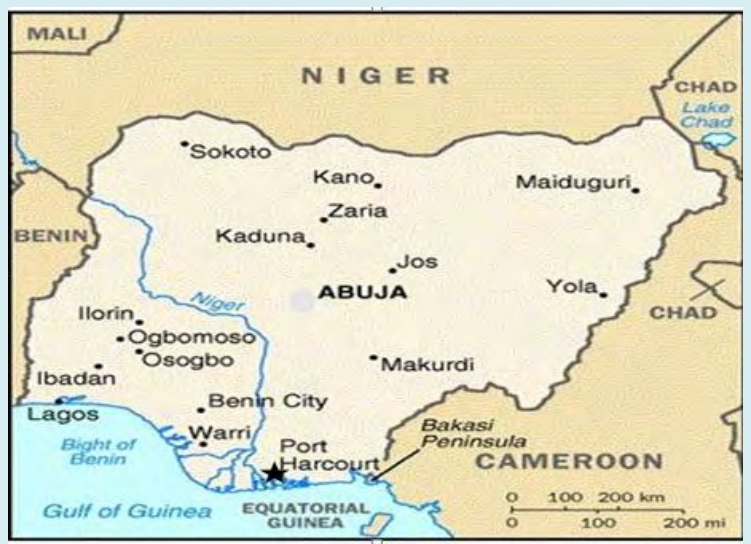

Figure 1: Map of Nigeria showing Port Harcourt [31]

\section{The Data Source}

The data used in this research was obtained from the International Institute for Tropical Agriculture (IITA) Ibadan, Nigeria. It comprises of secondary data on daily averages of rainfall (mm), air temperature $\left({ }^{o} C\right)$ and solar radiation (MJ/ $\mathrm{m}^{2}$ /day) recorded over Port Harcourt (South-South Nigeria) from $1^{\text {st }}$ January, 1977 to $31^{\text {st }}$ December 2012, a period of thirty six years. In order to boost the number of data points to be used for the analysis, cubic spline interpolation is used to convert the recorded daily averages used to hourly data [32]. Data smoothening has dual advantages; it reduces the sampling interval from 1 day ( 24 hours) to 1 hour and greatly increases the number of data points (from 365-8760) so that meeting the minimum requirement on the number of data points $(8,000-10,000)$ for non-linear analysis becomes trivial [33].
The secondary data on greenhouse emissions was obtained from Climate Analysis Indicators Tool's (CAIT) Climate Data Explorer, World Resource Institute in Washington, DC [34]. CAIT data derives directly from United Nations Framework Convention on Climate Change (UNFCCC) Secretariat. It comprises of annual Total GHG Emissions and $\mathrm{CO}_{2}$ emissions excluding Land-Use Change and Forestry (LULUCF) in metric tons of $\mathrm{CO}_{2}$ emission $\left(\mathrm{MtCO}_{2} \mathrm{e}\right)$ for Nigeria from 1977 to 2012 [35].

\section{Results and Discussion}

\section{Results}

Figures 2 shows the annual Total $\mathrm{CO}_{2}$ emissions Excluding Land-Use Change and Forestry (LULUCF) in metric tons of $\mathrm{CO}_{2}$ emission $\left(\mathrm{MtCO}_{2} \mathrm{e}\right)$ over Nigeria.

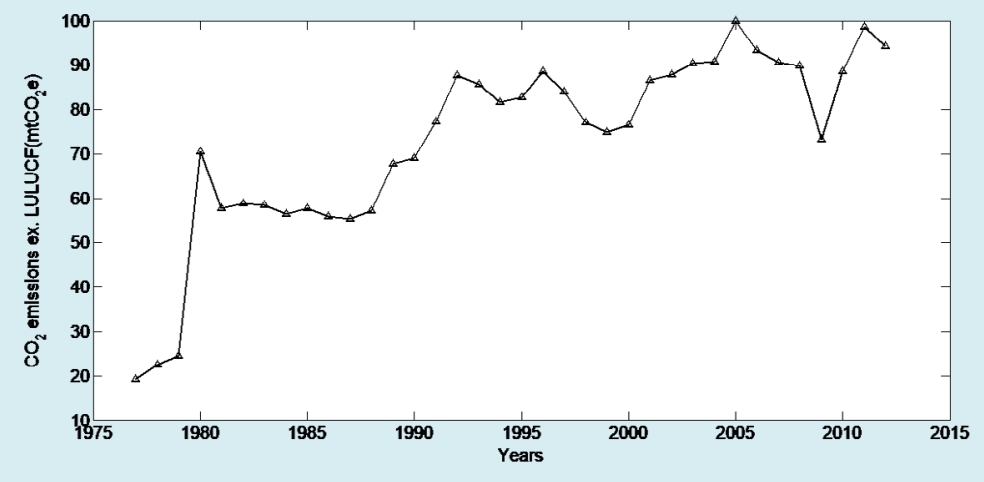

Figure 2: Total $\mathrm{CO}_{2}$ emissions excluding LULUCF from 1977-2012 in Nigeria.

It is clear to see that due to increased exploitation of oil and natural gas resources in the Niger Delta region of Nigeria, the annual $\mathrm{CO}_{2}$ emissions have greatly increased from 1977 to 2012. This calls for serious measures to be taken in order to curb the trend of global warming and climate change associated with this phenomena.

Figures 3(a) and 3(b) show a sample of the results for the determination of the time delay and embedding dimension using the methods of AMI and FNN respectively. 


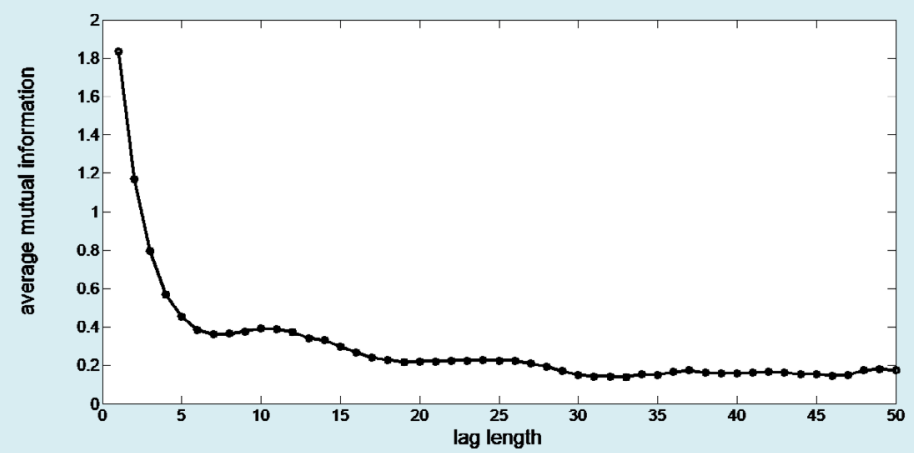

Figure 3(a): AMI function of the Average temperature for Port Harcourt (2010) with time delay, $\tau=7$

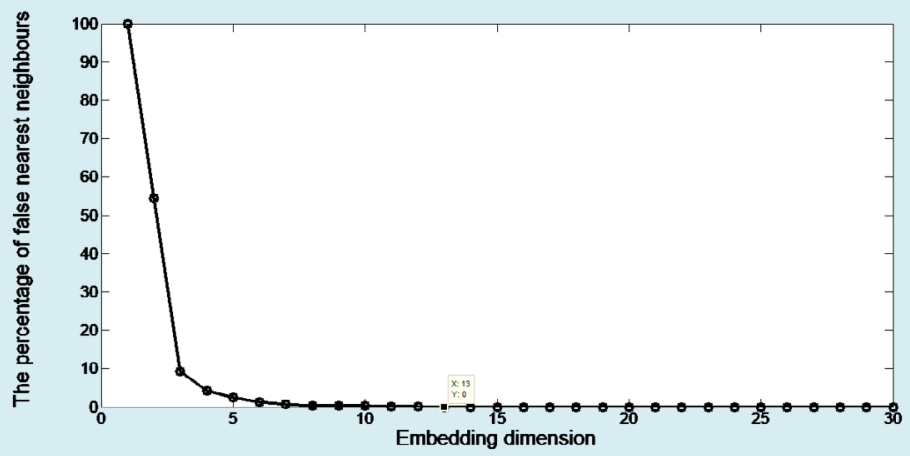

Figure 3(b): Percentage of FNN of the Average temperature for Port Harcourt (2010) with embedding dimension, $m=13$.

In computing the largest Lyapunov exponent $\lambda_{1}$, the algorithm is ran for a range of values of embedding dimension i.e. $\mathrm{m}=1$ to $\mathrm{m}$; obtained from the FNN plot $(\mathrm{m}=13)$. The range of values obtained constitute the Lyapunov exponents and the largest of this values is designated as the largest
Lyapunov exponent. Figure 4 shows the Lyapunov spectrum and the regression line drawn to evaluate the Lyapunov exponent for average temperature in Port Harcourt (2010) using $\tau=7$ and $\mathrm{m}=13$.

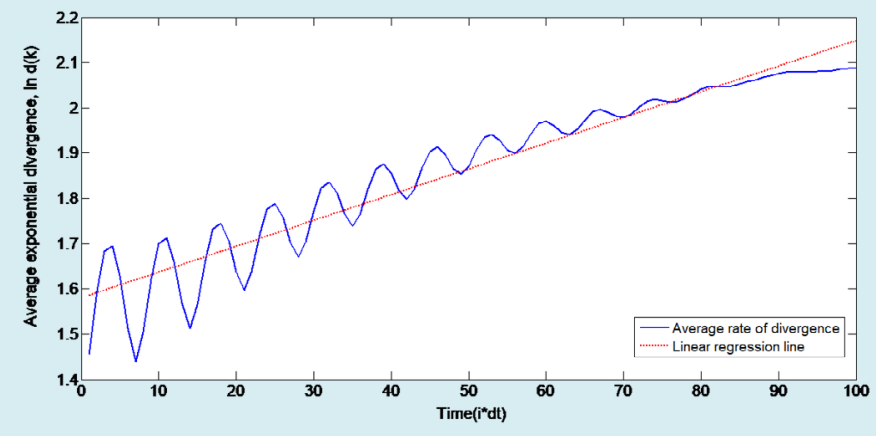

Figure 4: Estimation of the largest Lyapunov exponent from the Lyapunov spectrum for average temperature in Port Harcourt for $2010(\lambda=0.0299$ per day and $T=33.39$ days $)$.

Tables 1 shows the correlation coefficient between the Lyapunov exponent of the meteorological variables and time. 


\section{Physical Science \& Biophysics Journal}

\begin{tabular}{|c|c|c|}
\hline Variable & Correlation Coefficient & Trend \\
\hline Rainfall $(\mathrm{mm})$ & -0.4177 & Weak decreasing \\
\hline Average temperature $\left({ }^{\circ} \mathrm{c}\right)$ & -0.4729 & Weak decreasing \\
\hline Solar radiation $(\mathrm{MJ} / \mathrm{m} 2 /$ day) & -0.5597 & Decreasing \\
\hline
\end{tabular}

Table 1: Correlation coefficient between the predictability of the meteorological variables and time.

The negative correlation coefficient values recorded implies that the predictability of these meteorological parameters has a decreasing trend in the last three decades.
Tables 2 shows the results of the Mann-Kendall trend analysis of the predictability of the meteorological variables over Port-Harcourt from 1977 to 2012.

\begin{tabular}{|c|c|c|c|c|c|c|c|}
\hline Variable & Kendalltau & $\begin{array}{c}\text { Mann-Kendall } \\
\text { coefficient S }\end{array}$ & Z statistic & $\begin{array}{c}\boldsymbol{p} \text { - } \\
\text { value }\end{array}$ & $\begin{array}{c}\text { Trend description } \\
\text { (from Z value) }\end{array}$ & $\begin{array}{c}\text { Hypothesis test (h=1: } \\
\text { significant, h=0: not } \\
\text { significant) }\end{array}$ & $\begin{array}{c}\text { Trend } \\
\text { Significance }\end{array}$ \\
\hline Rainfall & -0.267 & -167 & -2.263 & 0.0237 & Decreasing trend & $\mathrm{h}=1$ & Significant \\
\hline $\begin{array}{c}\text { Average } \\
\text { temperature }\end{array}$ & -0.32 & -201 & -2.726 & 0.0064 & Decreasing trend & $\mathrm{h}=1$ & Significant \\
\hline Solar radiation & -0.367 & -231 & -3.133 & 0.0017 & Decreasing trend & $\mathrm{h}=1$ & Significant \\
\hline
\end{tabular}

Table 2: Mann-Kendall trend analysis of predictability of meteorological variables in Port-Harcourt from $1977-2012$.

The results in Table 2 shows negative values of Kendall tau correlation coefficient and Mann-Kendall coefficient (S) indicating a decreasing trend in the predictability of rainfall, average temperature and solar radiation over Port-Harcourt from 1977-2012. The significance of the results are further confirmed by the Z-statistic values whose absolute values are all greater than with the levels of significance ( $p$-value) all below 0.05. Table 3 shows the developed Sen's Model equations used to plot the trend in the annual predictability (T) of the three meteorological variables with time ( $\mathrm{t}$ ) in Port Harcourt.

\begin{tabular}{|c|c|c|}
\hline Variable & Model equations: $\mathbf{T}=\mathbf{Q t}+\mathbf{B}$ & Trend description \\
\hline Rainfall $(\mathrm{mm})$ & $\mathrm{T}=-0.1153 \mathrm{t}+245.834$ & Decreasing \\
\hline Average temperature $\left({ }^{\circ} \mathrm{c}\right)$ & $\mathrm{T}=-0.1671 \mathrm{t}-369.904$ & Decreasing \\
\hline Solar radiation $(\mathrm{MJ} / \mathrm{m} 2 /$ day $)$ & $\mathrm{T}=-0.511 \mathrm{t}+1046.8$ & Decreasing \\
\hline
\end{tabular}

Table 3: The developed Sen's Model equations for the linear-time trend evaluation.

The results in Table 3 all show negative slopes which is commensurate with decreasing trends in the predictability of rainfall, average temperature and solar radiation from
1977-2012. Figures 5, $6 \& 7$ show plots of the trends of predictability of the meteorological variables over Port Harcourt from 1977-2012.

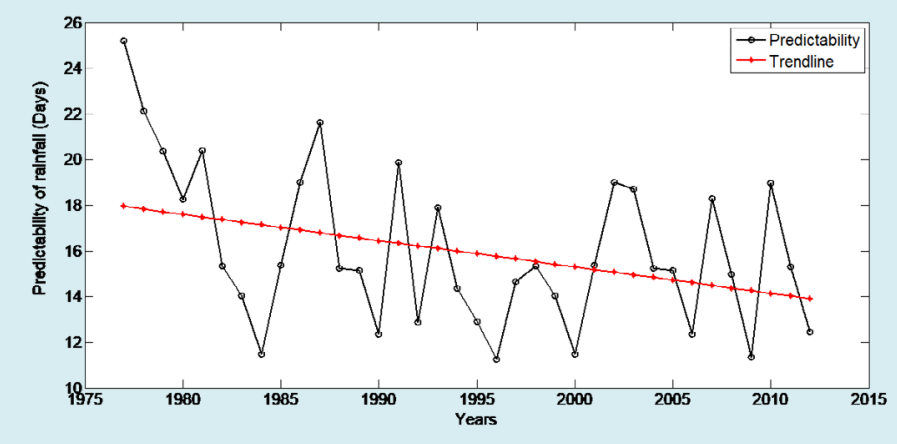

Figure 5: Predictability trend of rainfall in Port Harcourt (1977-2012). 


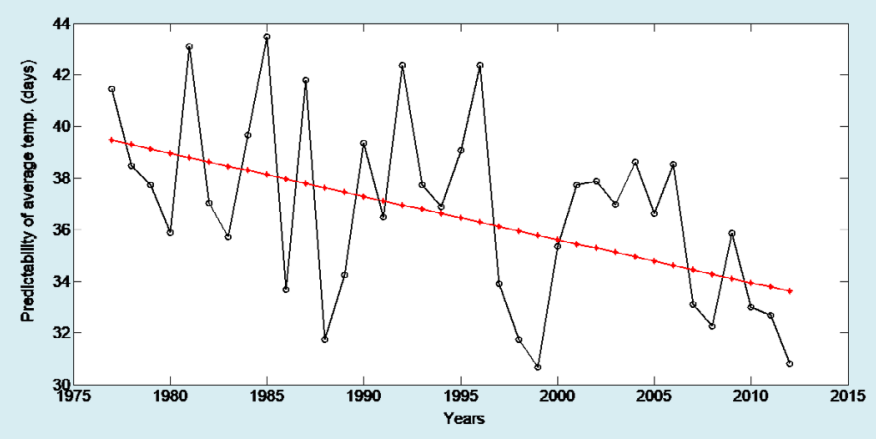

Figure 6: Predictability trend of average temperature in Port Harcourt (1977-2012).

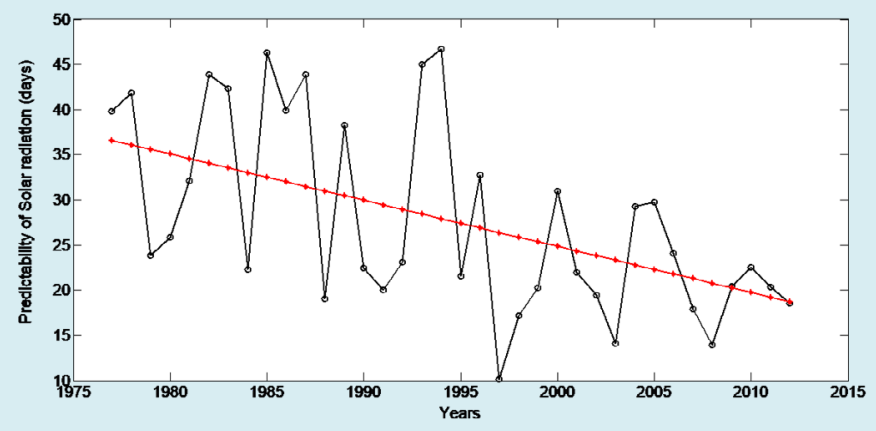

Figure 7: Predictability trend of solar radiation in Port Harcourt (1977-2010).

Tables 4 shows the correlation coefficient between the Lyapunov exponent of the meteorological variables and the total $\mathrm{CO}_{2}$ emissions in Port-Harcourt excluding LULUCF from 1977-2012.

\begin{tabular}{|c|c|c|}
\hline Variable & Correlation coefficient & Trend \\
\hline Rainfall $(\mathrm{mm})$ & -0.5219 & Decreasing \\
\hline Average temperature $\left({ }^{\circ} \mathrm{c}\right)$ & -0.2977 & Weak decreasing \\
\hline Solar radiation $(\mathrm{MJ} / \mathrm{m} 2 /$ day $)$ & -0.4553 & Weak decreasing \\
\hline
\end{tabular}

Tables 4: Correlation coefficient between the predictability of the meteorological variables and the total $\mathrm{CO}_{2}$ emissions over Port-Harcourt Nigeria.

The negative correlation coefficient values here also indicate that as the total $\mathrm{CO}_{2}$ emissions increase over the years, the predictability of these meteorological parameters decreases. Table 5 is a summary of the Mann-Kendall correlation and trend analysis between the predictability of meteorological variables and the $\mathrm{CO}_{2}$ emissions excluding LULUCF in Port-Harcourt from 1977-2012.

The results in Table 5 also show negative values of Kendall tau correlation coefficient and Mann-Kendall coefficient indicating decreasing trend in the predictability of rainfall, average temperature and solar radiation as the $\mathrm{CO}_{2}$ emissions increase over Port-Harcourt from 1977-2012. The significance of the results for rainfall and solar radiation are confirmed by the Z-statistic values whose absolute values are all greater than with their p-values all below 0.05 while that of average temperature is considered not significant as its Z-statistic value is less than 1.96 and its $p$-value is greater than 0.05 . Table 6 shows the developed Sen's Model equations used to plot the linear trend in the annual predictability of the meteorological variables $(\mathrm{T})$ in relation to the $\mathrm{CO}_{2}$ emissions (Y) over Port Harcourt from 1977 to 2012. 
Physical Science \& Biophysics Journal

\begin{tabular}{|c|c|c|c|c|c|c|c|}
\hline Variable & Kendalltau & $\begin{array}{c}\text { Mann- } \\
\text { Kendall } \\
\text { coefficient S }\end{array}$ & Z statistic & p-value & $\begin{array}{c}\text { Trend } \\
\text { description } \\
\text { (from } Z \\
\text { value) } \\
\end{array}$ & $\begin{array}{c}\text { Hypothesis test } \\
\text { (h=1: significant, } \\
\text { h=0: not } \\
\text { significant) }\end{array}$ & $\begin{array}{c}\text { Trend } \\
\text { Significance }\end{array}$ \\
\hline Rainfall & -0.2346 & -147 & -1.9899 & 0.0466 & $\begin{array}{c}\text { Decreasing } \\
\text { trend }\end{array}$ & $h=1$ & Significant \\
\hline $\begin{array}{c}\text { Average } \\
\text { temperature }\end{array}$ & -0.1546 & -97 & -1.3083 & 0.1908 & $\begin{array}{l}\text { Decreasing } \\
\text { trend }\end{array}$ & $\mathrm{h}=0$ & $\begin{array}{c}\text { Not } \\
\text { Significant }\end{array}$ \\
\hline Solar radiation & -0.2875 & -181 & -2.452 & 0.0142 & $\begin{array}{l}\text { Decreasing } \\
\text { trend }\end{array}$ & $\mathrm{h}=1$ & Significant \\
\hline
\end{tabular}

Table 5: Results of the Mann-Kendall correlation and trend analysis predictability of the meteorological variables and the total $\mathrm{CO}_{2}$ emissions over Port-Harcourt Nigeria.

\begin{tabular}{|c|c|c|}
\hline Variable & Model equations: $\mathbf{T}=\mathbf{Q Y}+\mathbf{B}$ & Trend description \\
\hline Rainfall $(\mathrm{mm})$ & $\mathrm{T}=-0.0608 \mathrm{Y}+20.2332$ & Decreasing \\
\hline Average temperature $\left({ }^{\circ} \mathrm{c}\right)$ & $\mathrm{T}=-0.0438 \mathrm{Y}+39.7526$ & Decreasing \\
\hline Solar radiation $(\mathrm{MJ} / \mathrm{m} 2 /$ day $)$ & $\mathrm{T}=-0.2511 \mathrm{Y}+44.6988$ & Decreasing \\
\hline
\end{tabular}

Table 6: The developed Sen's Model equations for the linear trend evaluation.

Figures 8, 6 \& 7 shows plots of the trends of predictability

1977-2012. of the meteorological variables over Port Harcourt from

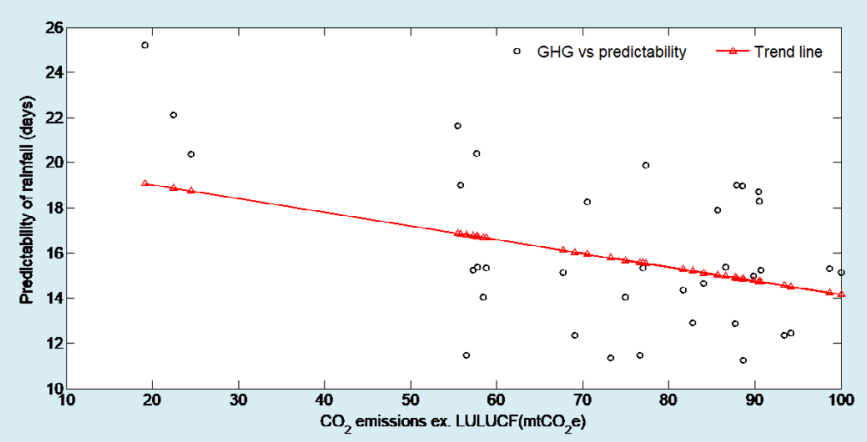

Figure 8: Predictability trend of rainfall with $\mathrm{CO}_{2}$ emissions in Port Harcourt (1977-2010).

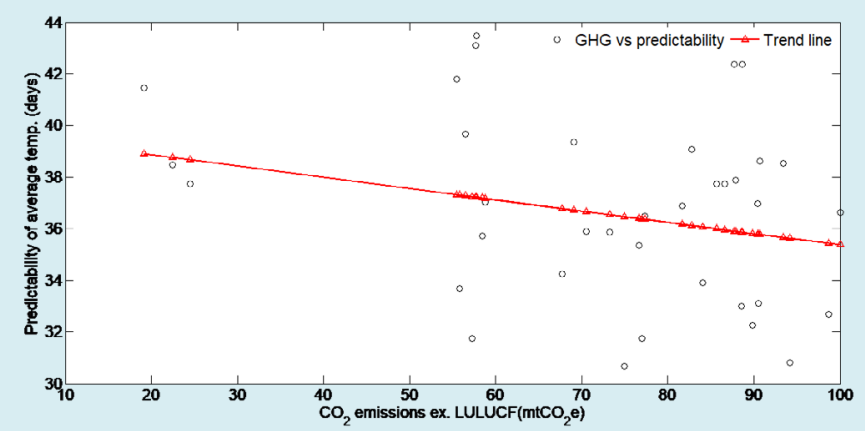

Figure 9: Predictability trend of average temperature with $\mathrm{CO}_{2}$ emissions in Port Harcourt (1977-2010). 


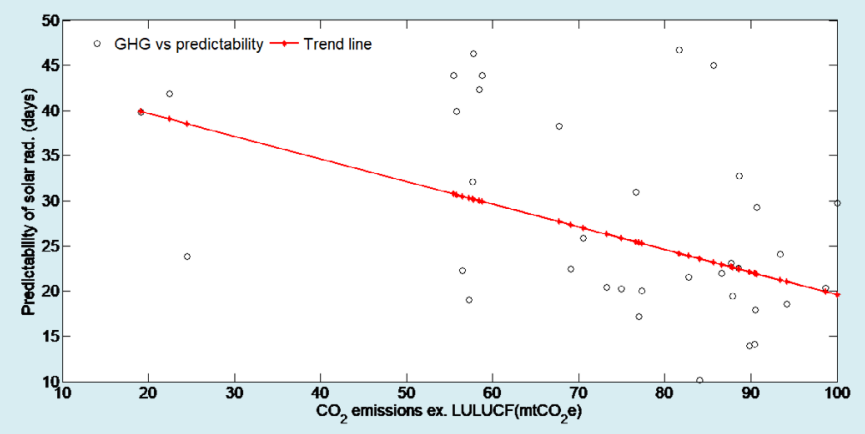

Figure 10: Predictability trend of solar radiation with $\mathrm{CO}_{2}$ emissions in Port Harcourt (1977-2010).

\section{Discussion}

From the nonlinear analysis carried out on rainfall, average temperature and solar radiation in Port Harcourt, it is observed that all the parameters show strong signatures of chaos, as their Lyapunov exponents are all positive. The trend of predictabilities are not linear and well defined as most of the parameters show random fluctuations in their annual Lyapunov exponents and predictability over the thirty six year period observed. From the results displayed in Tables 1 and 2, it is observed that the predictability of rainfall, average temperature and solar radiation in Port Harcourt from 19772012 show decreasing trends that are all significant. The Kendall tau, Man-Kendall Statistic (S), the time correlation coefficients (Table 1) and the Sen's slope estimate (Q) are all negative with their values clearly indicating decreasing trends, this is further illustrated in Figures 5, 6 and 7. The Z-statistic values are also negative and their absolute values are all greater than $Z_{\alpha /}=1.96$ with the levels of significance all less than 0.05 ; thus rejecting the null hypothesis and confirming the significance of the decreasing trends in the predictability of the three meteorological parameters over the last three decades.

In a similar vein, the results in Table 4 and 5 shows that the correlation of the predictabilities of the three meteorological parameters with the total $\mathrm{CO}_{2}$ emissions indicates that an increase in greenhouse emissions into the atmosphere over Port Harcourt has caused more chaos in the weather leading to a decrease in the predictability of rainfall, average temperature and solar radiation over Port Harcourt over the last three decades. This is confirmed by the negative values of the Kendall tau, Man-Kendall Statistic (Table 5) and the Sen's slope estimate with their values clearly indicating decreasing trends as illustrated in Figures 8, 9 and 10. The Z-statistic values are also negative, however, while the absolute values of the Z-statistic for rainfall and solar radiation are greater than $Z_{\alpha /}=1.96$ with the levels of significance ( $p$-value) all less than 0.05 indicating significance of the trend, that of average temperature for Port Harcourt is greater than 1.96, with $p$-value greater than 0.05 indicating an insignificance in the trend of correlation of average temperature with greenhouse gas emissions over Port Harcourt. Rainfall in Port Harcourt exhibits double maxima regime with high variability with peaks in July and September. Thus, since Port Harcourt is coastal town with cool Atlantic south-westerly winds in abundance, an increase in $\mathrm{CO}_{2}$ emissions leading to global warming from anthropogenic activities tends to affect the predictability of rainfall and solar radiation much more than that of average temperature [36].

The implication of these results showing significant decreasing trends in predictability of these meteorological parameters is that the increase in activities of oil and gas exploration in the Niger Delta region of Nigeria has adversely affected the climate in that region; the weather has become more chaotic, with more random fluctuations with extreme viral conditions to be expected in the nearest future. Heavy and random rainfall pattern, high tides, increased solar radiation due to the continuous depletion of the ozone layer, violent winds and hurricanes etc. are also to be expected in the years to come. These could lead to natural disasters such as flooding, famine, outbreak spread of diseases, collapse of existing infrastructural facilities like buildings, roads, bridges, failure in weather forecasting by meteorological agencies, unemployment as a result of economic setbacks and a drop in the nations GDP since oil is the mainstay of Nigeria's economy.

This work seems to be one of the pioneer works on this subject. However the results in this work complements that obtained by Joice and Thamilharazan in 2012 [37], who investigated the effect of the Tsunami on the trend of atmospheric circulation and predictability related to the monsoon rainfall in Tamil Nadu, India before and after the Tsunami. The results of their work also revealed an increase in the Lyapunov exponents (decrease in predictability) of rainfall from 0.5604 /day (1.78 days) before Tsunami to 
0.8606 /day (1.16 days) after the Tsunami. The increase in the values of the Lyapunov exponents suggests that the Tamil Nadu monsoon rainfall has certainly been disturbed by the occurrence of the Tsunami in the area. Hence it is recommended that more adequate measures be taken by the Nigerian government especially as regards to gas flaring and oil spillage to combat climate change as stated in the Fourth Assessment Report of the Intergovernmental Panel on Climate Change (IPCC) [37].

\section{Conclusion}

The results of this work shows that rainfall, average temperature and solar radiation in Port Harcourt from 1977-2012 all show strong signatures of chaos and their predictability is decreasing significantly as the years go by. Thus we can conclude that, based on the observed decreasing trends and their statistical significance confirmed, the accuracy of weather forecasts over Port Harcourt is bound to suffer much failure as a result of greenhouse gas emissions from oil exploration and refining activities in the nearest future. Hence adequate legislations must be passed by the Nigerian government to compel the oil companies cut down greenhouse gas emissions in order to curb the effect of climate change in the Niger Delta region of Nigeria.

\section{References}

1. Lorenz EN (1961) Dimension of weather and climate attractors. Letters to Nature 353: 241-244.

2. Lorenz EN (1963) Deterministic Non-periodic Flow. Journal of the Atmospheric Sciences 20(2): 130-141.

3. Lorenz EN (1991) The General Circulation of the Atmosphere: An Evolving Problem. Tellus 43(4): 8-15.

4. Poincaré H, Rontani D, Citrin S (2013) Lecture 1: Introduction to chaos. School of Electrical and Computer Engineering, Georgia Institute of Technology, Atlanta, Georgia, pp: 1-50.

5. Rothman D (2006) Nonlinear dynamics I: chaos- 15 Lyapunov exponents. MIT open courseware on Dynamics and Relativity, Massachusetts, USA.

6. Karytinos A (1999) A Chaos Theory and Nonlinear Dynamics Approach to the Analysis of Financial Series a Comparative Study of Athens and London Stock Markets. $\mathrm{PhD}$ thesis, University of Warwick, Warwick, UK.

7. Stehlík J (2006) Searching for Chaos in Rainfall and Temperature Records - a Nonlinear Analysis of Time Series from an Experimental Basin. Na Sabatce 17(143): 6.
8. Aurell E, Boffetta G, Crisanti A, Paladin G, Vulpiani A (1997) Predictability in the large: an extension of the concept of Lyapunov exponent. J Phys A Math Gen 30(1): $1-26$.

9. Apata TG, Ogunyinka AI, Sanusi RA, Ogunwande S, (1998) Effects of Global Climate Change on Nigerian Agriculture: An Empirical Analysis. Climate Research 11: 30-46.

10. Strahler AN (1971) Physical Geography. $3^{\text {rd }}(E d n$.$) , John$ Wiley and Sons, New York, pp: 97-98.

11. IPCC, Fourth Assessment Report of the Intergovernmental Panel on Climate Change (AR4): Summary of Policymakers.

12. Wang J, Chameides B (2005) Global Warning's Increasingly Visible Impacts. Environmental Defense, USA, pp: 1-43.

13. Monckton C (2015) Chaos Theory and global warming: Can Climate be predicted?

14. Rosenstein M, Collins J, De Luca C (1993) A practical method for calculating largest Lyapunov exponents from small data sets. Physica D: Nonlinear Phenomena 65(12): $117-134$.

15. Packard N, Crutchfield J, Farmer J, Shaw R (1980) Geometry from a Time Series. Phys Rev Lett 45: 712.

16. Takens F (1980) Detecting Strange Attractors in Turbulence. Lecture Notes in Mathematics 898: 366381.

17. Cellucci CJ, Albano AM, Rapp PE (2003) Comparative study of embedding methods. Phys Review E 67: 1-14.

18. Kennel M, Brown M, Abarbanel H (1992) Determining embedding dimension for phase-space reconstruction using a geometrical construction. Phys Rev A 45(6): 3403-3411.

19. Echi MI, Tikyaa EV, Isikwue BC (2015) Dynamics of Rainfall and Temperature in Makurdi. International Journal of Science and Research 4(7): 493-499.

20. Cecen A, Erkal C (2008) Effects of Trend and Periodicity on the Correlation Dimension and the Lyapunov Exponents. Int J Bifurcation \& Chaos 18(12): 3679-3687.

21. Fuwape IA, Ogunjo ST, Oluyamo SS, Rabiu AB (2016) Spatial variation of deterministic chaos in mean daily temperature and rainfall over Nigeria. Theor Appl Climatol 130: 119-132. 
22. MathBits (2015) Statistics 2-Correlation Coefficient and Coefficient of Determination.

23. McBean E, Motiee H (2008) Assessment of Impact of Climate Change on Water Resources: A Long Term Analysis of the Great Lakes of North America. Hydrology and Earth System Sciences 12: 239-255.

24. Christoph A, Frei S (2015) Analysis of Climate and Weather Data: Trend Analysis.

25. Olofintoye O, Sule BF (2010) Impact of Global Warming on the Rainfall and Temperature in the Niger Delta of Nigeria. USEP Journal of Research Information in Civil Engineering 7(2): 33-48.

26. Khambhammettu P (2005) Mann-Kendall Analysis, Annual Groundwater Monitoring. Report of Hydro Geologic Inc 35.

27. Salmi T, Määttä A, Anttila $P$, Ruoho-Airola T, Amnell T, et al. (2002) Detecting Trends of Annual Values of Atmospheric Pollutants by the Mann-Kendall Test and Sen's Slope Estimates: The Excel Template Application Makesens. Finnish Meteorological Institute Publications on Air Quality 31: 25.

28. Burkey J (2006) A non-parametric monotonic trend test computing Mann-Kendall Tau, Tau-b, and Sen's Slope written in Mathworks-MATLAB implemented using matrix rotations. Department of Natural Resources and
Parks, Science and Technical Services section, Seattle, Washington, USA,

29. Port Harcourt (2015a). Wikipedia.

30. Port Hartcourt (2015b) Port Harcourt Refining Company.

31. Port_Harcourt_Map (2019).

32. Kiusalaas J (2012) Numerical Methods in Engineering with MATLAB. Cambridge University Press, UK, pp: 116119.

33. Ekmann J, Ruelle D (1985) Ergodic theory of chaos and strange attractors. Rev Mod Phys 57: 617-656.

34. CAIT Climate Data Explorer (2015) Country Greenhouse Gas emission data. World Resources Institute, Washington D.C.

35. UNFCCC (2013) Time Series - Annex I United Nations Framework Convention on Climate Change.

36. Uko ED, Tamunobereton-Ari I (2013) Variability of Climatic Parameters in Port Harcourt, Nigeria. Journal of Emerging Trends in Engineering and Applied Science 4(5): 727-730.

37. Joice GHR, Thamilhazan K (2012) Impact of Tsunami on Tamil Nadu Monsoon Rainfall. APRN Journal of Science and Technology 2(2): 96-97. 